\title{
A reflection on EUSA sexual harassment campaigns
}

\section{Chris Belous}

I am a fourth-year German and Linguistics student who was elected as Women's Liberation Convenor for Edinburgh University Students' Association (EUSA) for the academic year 2016/17. My work involves representing women and non-binary students on issues affecting them as students who experience gender-based discrimination at the University and in wider society. This includes everything from organising demonstrations against street-based sexual harassment and sexual violence, running workshops and film screenings, and consulting on policy which impacts women and non-binary students - for instance, policy around issues of gender-based violence such as sexual violence and abuse.

Sometimes you can forget that things have come a long way in the space of a few years. Changes can be small, and they can take so much energy and time to make, that you forget that any change was actually made, and that the positive effects were actually felt. Within an old and well-established academic institution like the University of Edinburgh (UoE), it can sometimes feel like change is impossible - but in some aspects we've come a long way since 2013, when Edinburgh University Students' Association conducted a survey which found that a third of respondents had experienced some form of sexual harassment during their time at Edinburgh.

The past few years have seen sexual violence at universities in the UK become a much more visible issue, one which 
many people - women, survivors of sexual harassment and abuse, students, academics, union staff - have been working to combat all over the country. At Edinburgh this has been no different, although we still have work to do.

Since 2014, there have been several campaigns run at UoE and through the Students' Association to tackle the high amount of sexual harassment and sexual violence on our campuses and that people face during their university lives. The core three are the 2014 Students' Association Monsters campaign, the 2015 Students' Association Consent campaign jointly run with Sexpression Edinburgh, and the 2016 No One Asks For It (NOAFI) campaign jointly run by UoE, the Students' Association and Edinburgh University Sports Union (EUSU).

In this piece, I want to discuss my views of the merits of these campaigns, where we are at now, and the challenges we faced and continue to face in fighting sexual harassment and sexual violence in the context of academia.

The first campaign, coming out of the Students' Association's sexual harassment survey, was mostly a marketing one, centred around a set of cartoon monsters with the slogan, "Have you seen this monster?" It was designed to call attention to less obvious harassment, like unwanted grinding in clubs, and stalking, and it encouraged students to report incidents. Anecdotal evidence would suggest that it was effective in highlighting i ssues, raising awareness and encouraging people to come forward about any problems.

This is positive - considering that lack of awareness about what counts as problematic behaviour has been part of the issue for as long as rape culture has existed, it's important to have marketing campaigns which try to reverse this. "Consent", for example, just hasn't been talked about in UK schools until very recently. The year this campaign was launched was also a particularly key year for fighting rape culture and lad culture at Edinburgh. Eve Livingston, the then-Vice President Societies and Activities, was also running a series of talks and workshops on these topics in the light of veterinary school students making rape jokes at women students and the news which came to light of the extremely disgusting misogyny, transphobia and threats of violence against women propagated by the now long-gone Edinburgh chapter of the DKE (Delta Kappa Epsilon) fraternity.

The Monsters campaign and other coinciding work also attempted to highlight reporting procedures and other sources of support you could turn to, like Edinburgh Rape Crisis Centre. However, changing attitudes and behaviours regarding sexual violence is a slow process - undoing patriarchy is a lifelong task, after all, and while the Monsters campaign had its successes, more work was unfortunately needed to reach more students.

In 2014 we saw the resurgence of the Edinburgh branch of student-led sex and relationships education (SRE) charity Sexpression on campus and their work both in schools around Edinburgh and among UoE students on raising awareness about consent and prevention of sexual harassment and abuse. The group was asked by the Students' Association to help out with another campaign, starting in 2015 , which involved some marketing and also the presence of a fortnightly stall at Big Cheese, Potterrow's big Saturday student club night, where Sexpression volunteers would chat to students about consent and related issues, as well as giving out freebies (including free condoms, temporary tattoos and badges) with one of three slogans on them - "The way I dress is not a yes," "You can't always get what you want," or "It's not me. It's you". The stalls have been hugely successful so far and are in their second year of existence as of 2016.

This campaign had less of a focus on reporting forms of harassment and more on education, especially at grassroots level. Rather than being a poster campaign alone, it also involved direct face-to-face 


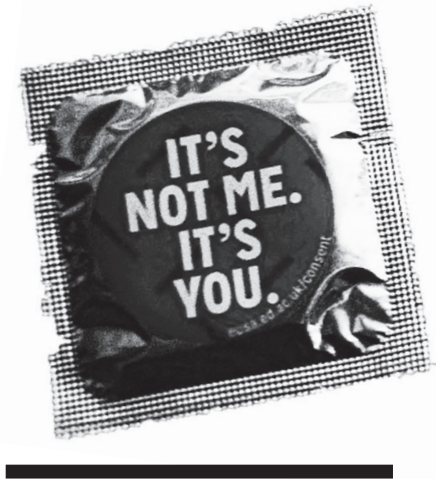

Free condoms with slogans from the Sexpression and Students' Association consent campaign. Photo: Chris Belous.

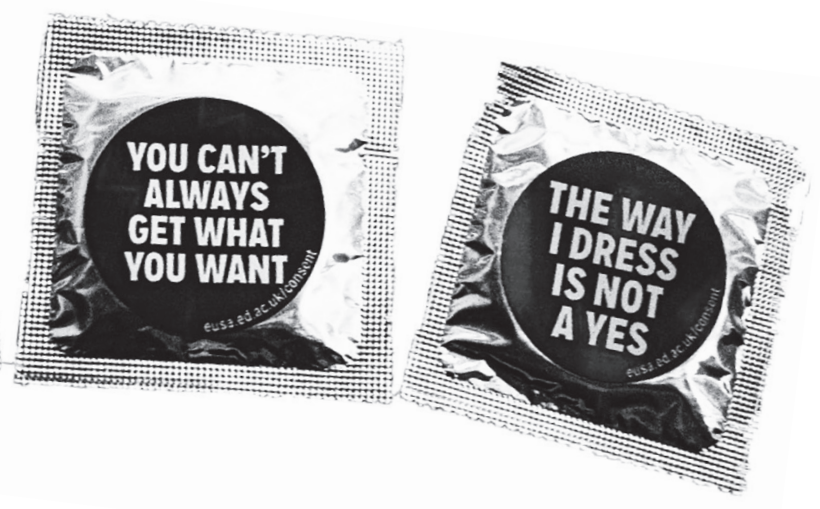

outreach with a group of people who might not otherwise engage much with Students' Association campaigns as well as those who do. Week after week, the stalls are extremely popular and a majority of students have now heard of Sexpression and know the campaign and the stall.

Very early on in the campaign, there was one story told to Sexpression about how a person was being harassed on the dance floor but remembered the anti-harassment temporary tattoo they were wearing which they had got from the Sexpression stall, and this made them feel empowered enough to report the harasser. This and the fact the stall is reaching hundreds of students twice a month, especially freshers, in a fun setting but in a setting where harassment and abuse is arguably especially frequent, is incredibly powerful.

Both the Monsters and the Consent campaign had their fun elements - the cute cartoons, the sassy slogans, the freebies. They were also both Students' Associationdriven - but what about the University? Cue an attempt by the University during the 2015/2016 academic year to launch a campaign around "dignity and respect" - a campaign which the then-sabbatical officers chose not to take part in and promote. Why? Because, in my view and that of many students, staff and sabbatical officers, it failed to address the problems of violence, harassment and assault and instead skirted around the issue by focusing on more nebulous concepts of "respect".

While this is in line with the UoE's Dignity and Respect Policy, it is too vague to have much impact, and also isn't particularly radical. It's not an anti-violence campaign if you don't say the word. Nothing will change if you don't confront a problem head on. For the University to frame the campaign in the way they did was, arguably, a method of hiding a problem and of escaping responsibility. And that was an issue.

The University came back later on having changed direction, this time acknowledging that something more specific was needed: this is where the No One Asks For It campaign has come from. This UoEdriven campaign was interesting in two ways - it brought together the University, the Students' Association and the Sports Union, and it was also designed by an external marketing team. What resulted was a microsite with information about the principles behind the campaign and what it was aiming to combat and raise awareness of, a page where you could sign

175 EqualBITE A reflection on EUSA sexual harassment campaigns 
a pledge to fight sexual harassment and sexual violence and be an "active bystander", pages with information on consent and where to go for support, and information about UoE's reporting mechanisms and what the Students' Association offers.

There was also a very slick-looking marketing campaign, centred around some quite provocative slogans (“Grope me," proclaims one poster, with the slogan "No one asks for it" written underneath) all accompanied by some brightlycoloured lips. The video made for the campaign sees a voice-over with such slogans as these being spoken over quickly-changing lips and then "No one asks for it" flashing up at the end with some quite spiky music.

The campaign is designed to shock people into thinking about the issue, and while the content in its presentation and bluntness is potentially quite triggering for
HAVE YOU SEEN ANY OF THESE MOWSIEBS?
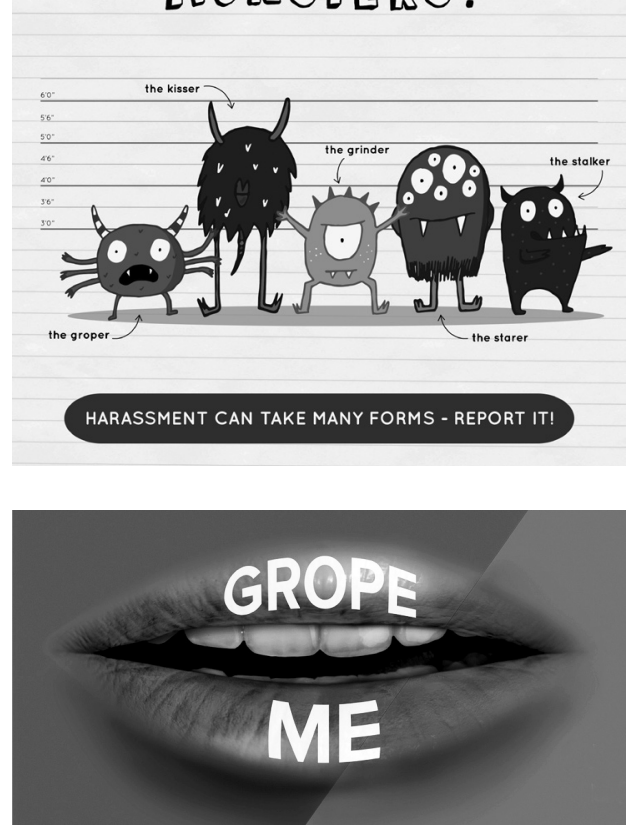

Images courtesy of Edinburgh University Students' Association on social media and in student emails, and through the face-to-face outreach conducted by various students and staff from the three partner organisations in buildings around all the different UoE campuses. The face-to-face outreach was designed to raise awareness of the campaign and encourage staff and students to sign the online pledge - the aim was to get 4,000 signatures. But what happens, students would ask (and so do I), when you sign? What happens when you reach the goal? Nothing, really.

This is where a well-intentioned campaign unfortunately falls short, partly also because substantive change on these kinds of issues has always been difficult to achieve - it is at best slow-moving and at worst stagnant, and there are bureaucratic obstacles to contend with too.

The pledge is a pleasant gesture, but arguably it also survivors of sexual violence, it was received mostly quite well at the consultation stage. The campaign was also meant to lead to training being provided for staff and students around issues of sexual violence and support, which as of writing has been rolled out to students who are in positions of leadership and is being developed in some form for staff.

Students will have been exposed to this campaign in two ways - through the marketing being put up around campus and in Students' Association buildings, as well as means very little. The fact this is happening alongside UoE reforming its Dignity and Respect Policy (a set of guidelines, not very specific ones at the moment, which function as a kind of code of conduct for staff and students; it provides guidelines along which people might be disciplined) and finally adding a clear section with guidelines on reporting and support for those affected by sexual violence on the UoE website means there is some progress, but it's all very surface level. 
Survivors of sexual violence still may not feel comfortable using the University or Students' Association's systems to report incidents due to issues around confidentiality, stigma and safety. It may be difficult to trust the outcome of an investigation into harassment, assault or rape when you are never allowed to find out how the perpetrator has been disciplined (if they have been at all).

It is worth pointing out here that none of these campaigns are without their flaws. The Monsters campaign, with its cutesy cartoons supposed to represent some quite heinous acts, seems quite jarringly gentle compared to the subject matter. The Sexpression Consent campaign has been brilliant for education and awareness, but does not challenge structural issues. And No One Asks For It has been rolled out only to a muted reception, with training for staff not yet fully in existence, and employs potentially quite problematic imagery and techniques to get its message across. There is the argument that these campaigns were all suitable in their purpose and audience, and that they have all been important steps in raising awareness and reducing sexual violence in the University setting. And they have all been relatively effective in raising awareness and at least challenging attitudes and trying to change them. But what's next if sexual violence is still happening and survivors don't feel safe enough to come forward?

In some ways, it's OK that none of these campaigns have really effected structural change within the University, because that wasn't their goal. Changing attitudes is just as important as changing structures, since the two go hand in hand. But we have now had three campaigns in the past three years which have focused on attitudes and awareness - so what's needed now is to make sure changing attitudes are reflected in improved reporting and support structures, and that survivors of sexual violence are safe alongside sexual violence being prevented.
As Women's Convenor, some of the work I have been doing this year alongside our sabbatical officers and Students' Association staff has centred around priorities in terms of reporting and support mechanisms, based on best practice advice and work from campaigns like \#StandByMe from the NUS (National Union of Students). Some priorities involve transparency and accountability on the side of the University in terms of publishing reporting statistics and making the disciplinary outcome known to the person who reported an issue, as appropriate. Other priorities aim to ensure that survivors have their needs met in terms of special circumstances and reasonable adjustments, and more. This work is in its early stages and some priorities may be harder to achieve than others, especially in an academic institution where changes take time due to bureaucracy, never mind anything else.

Work is also being done within the Students' Association on the specific issues surrounding staff-student cases of sexual violence and harassment, and I am hoping to focus more on other forms of support for survivors in the coming months (for instance, guidance on how peers and staff can support survivors on a more day-to-day basis, and the possibility of an informal survivor support network). It's clear that a lot of work has been done in the last three years on prevention and reporting, but not so much on other forms of support for people who have been affected - so not only is there work to be done at the structural level, but also on the interpersonal level.

All of this is, ultimately, promising. And I do think it is fair to say that we have come very far in the past few years with regard to awareness of sexual violence and consent. People are becoming more and more willing to confront their own and other people's behaviours, and people take sexual violence, violence against women and marginalised genders in particular, more seriously now than in the past. What is curious though is that the University, even with the advent of No One Asks For It, has tried to take a 
back seat, and it seems there has not been a lot of willingness to confront problems head on. The original video campaign on "dignity and respect" completely missed the point, and while No One Asks For It discusses sexual violence more explicitly, it basically boils down to yet another marketing campaign with some training.

It is not clear what actual change will come from the pledge which some have seen as meaningless. No One Asks For It is useful - it is the University trying to take a step in the right direction, and a pressure point students and staff can use to make them enact structural change (as in, we can say: "Now that you have done this, students support it and also support further change building on this"). But why did it take some parts of the University so long to even begin to confront sexual violence openly? And why is it that the University, with all its power and all its desire to show off its reputation for being a progressive and innovative institution, has only produced a marketing campaign so far and updated their website a bit, but nothing more?

The potential reasons could be reputation and the neoliberalisation of education, as some academics have argued (Whitley \& Page, 2015). The thinking could be that if the University of Edinburgh or other universities admit that they are institutions with a hidden problem with sexual violence, then they would lose reputation and trust. Therefore fewer people would "buy into" the University, as students, academics and indeed investors, and the University would lose out. But the reality is that the opposite is true: if the University were to be explicit in their admission that we have an issue to solve, and if the University were explicit in its attempts to improve its own accountability, then more people, especially and most importantly survivors of sexual violence, would trust the institution they are supposedly "buying into".

The very notion of "buying into" an educational institution is of course problematic. The commoditisation of education in recent years and the growing treatment of students as "customers" is incredibly dangerous for education and academia, and generally signifies a move towards academia being about capitalist worth rather than the well-being and development of students, and indeed staff, who walk a university's corridors. This means initiatives which don't directly benefit a university (i.e. don't bring it money or better reputation) might fall to the bottom of the pile. Which is why change can be slow, and universities can be reluctant to tackle problems openly and head-on.

It doesn't have to be like this, and this is why I and my fellow Liberation Convenors are working so hard on structural change within the University this year in all kinds of ways relating to gender, race, disability and sexuality, alongside staff from both the Students' Association and UoE. Progress is slow. It can indeed feel like not much has changed. But three years of anti-sexual violence campaigns definitely have not amounted to nothing.

What needs to happen now is that the University of Edinburgh as a whole comes to understand what role the institution has to play alongside work on increasing awareness and changing attitudes, because they have a duty of care and responsibility to their students which extends beyond the realm of money.

This is already the case among many staff members - there are of course many who do take their duty of care towards students very seriously and argue that academia must remain about the education and not the finance. But this culture needs to be something the University of Edinburgh stays true to and takes on as a whole. And it needs to make sure it is open, that it listens to its students - who want safety as well as a foot on the graduate career ladder - when we say, "You need to do more than this".

I hope they do listen. 